\title{
External validation of a prehospital risk score for critical illness
}

\author{
Daniel R. Kievlan ${ }^{1,2^{*}}$, Christian Martin-Gill ${ }^{3}$, Jeremy M. Kahnn ${ }^{1,2}$, Clifton W. Callaway ${ }^{3}$, Donald M. Yealy ${ }^{3}$, \\ Derek C. Angus ${ }^{1,2}$ and Christopher W. Seymour ${ }^{1,2,3}$
}

\begin{abstract}
Background: Identification of critically ill patients during prehospital care could facilitate early treatment and aid in the regionalization of critical care. Tools to consistently identify those in the field with or at higher risk of developing critical illness do not exist. We sought to validate a prehospital critical illness risk score that uses objective clinical variables in a contemporary cohort of geographically and temporally distinct prehospital encounters.
\end{abstract}

Methods: We linked prehospital encounters at 21 emergency medical services (EMS) agencies to inpatient electronic health records at nine hospitals in southwestern Pennsylvania from 2010 to 2012. The primary outcome was critical illness during hospitalization, defined as an intensive care unit stay with delivery of organ support (mechanical ventilation or vasopressor use). We calculated the prehospital risk score using demographics and first vital signs from eligible EMS encounters, and we tested the association between score variables and critical illness using multivariable logistic regression. Discrimination was assessed using the AUROC curve, and calibration was determined by plotting observed versus expected events across score values. Operating characteristics were calculated at score thresholds.

Results: Among 42,550 nontrauma, non-cardiac arrest adult EMS patients, 1926 (4.5\%) developed critical illness during hospitalization. We observed moderate discrimination of the prehospital critical illness risk score (AUROC $0.73,95 \% \mathrm{Cl}$ $0.72-0.74$ ) and adequate calibration based on observed versus expected plots. At a score threshold of 2, sensitivity was 0.63 (95\% Cl 0.61-0.75), specificity was 0.73 (95\% Cl 0.72-0.73), negative predictive value was 0.98 (95 \% Cl 0.98-0.98), and positive predictive value was 0.10 (95\% Cl 0.09-0.10). The risk score performance was greater with alternative definitions of critical illness, including in-hospital mortality (AUROC 0.77, $95 \%$ Cl $0.7-0.78$ ).

Conclusions: In an external validation cohort, a prehospital risk score using objective clinical data had moderate discrimination for critical illness during hospitalization.

Keywords: Clinical decision support systems, Critical illness, Emergency medical services, Forecasting, Prognosis, Triage

\section{Background}

Emergency medical services (EMS) agencies transport over 28 million patients per year in the United States [1]. Many of these patients have critical illness and experience substantial morbidity and mortality during subsequent hospitalization. The recognition of critical illness during prehospital care by EMS could lead to redistribution of patients to regional centers of excellence or prompt specific treatment before hospital

\footnotetext{
*Correspondence: kievlandr@upmc.edu

${ }^{1}$ Department of Critical Care Medicine, University of Pittsburgh School of Medicine, 3550 Terrace Street, Scaife Hall \#607, Pittsburgh, PA 15261, USA ${ }^{2}$ Clinical Research, Investigation, and Systems Modeling of Acute Illness (CRISMA) Center, Pittsburgh, PA, USA

Full list of author information is available at the end of the article
}

arrival [2-5]. These strategies better match patient needs with critical care resources and are used in many timesensitive conditions such as traumatic injury, acute cardiovascular disease, and cardiac arrest [6,7].

Yet, the recognition of high-risk prehospital patients is challenging for clinicians. In the brief prehospital time interval, paramedics' subjective assessments may not adequately discriminate patients who require hospital admission [8], and combinations with objective data offer only modest improvement [9]. Another approach is to use only objective prehospital data in risk assessments, but these may be missing or perform poorly as single measurements [10]. 
In prior work, a prehospital critical illness risk model used multiple objective, commonly recorded variables and adequately predicted the development of critical illness during hospitalization in a regional EMS system [11]. Although internally validated and tested in the emergency department [12], this model has yet to be externally validated using temporally and geographically distinct EMS data. We sought to validate model performance in a contemporary cohort of 21 EMS agencies transporting to 9 hospitals in an integrated healthcare system.

\section{Methods}

\section{Study design, population, and setting}

The institutional review board of the University of Pittsburgh approved the study with a waiver of informed consent. Following the Transparent Reporting of a multivariable prediction model for Individual Prognosis or Diagnosis (TRIPOD) recommendations for external validation of clinical risk scores [13-15], we linked EMS encounters from 21 agencies to inpatient electronic health records (EHRs) at 9 hospitals of the UPMC health system from January 2010 to December 2012. All EMS agencies received medical command in a two-tier system through the UPMC Department of Emergency Medicine, with on-scene medical care primarily provided by paramedics trained in advanced life support. Standardized prehospital electronic records of these encounters are stored in a secure repository (emsCharts, Warrendale, PA, USA), and they were linked to hospital EHR data using hierarchical matching (Cerner PowerChart; Cerner Corporation, North Kansas City, MO, USA) as previously described [16]. We included only scene-to-hospital transports of adult patients $\geq 18$ years of age. We excluded transports for cardiac arrest, trauma, burn, or falls or EMS records that lacked adequate clinical documentation to determine the prehospital risk score. We also excluded duplicate encounters and data from three geographically distinct hospitals that each received fewer than ten EMS transports from participating agencies.

\section{Variable definitions}

We defined the primary outcome of critical illness during hospitalization as intensive care unit (ICU) location stated in the EHRs with concomitant delivery of organ support (either mechanical ventilation or vasopressor use). The delivery of mechanical ventilation was identified using intubation, extubation, and tracheostomy events and ventilator mode data in the EHRs. Vasopressor use was defined as the administration of vasoactive agents (e.g., norepinephrine, dopamine, epinephrine) by infusion for more than $1 \mathrm{~h}$ recorded in the EHRs.

\section{Model assessment and data analysis}

We determined the prehospital risk score among eligible EMS encounters using demographics and the initial prehospital vital signs. Risk score variables, including age, sex, respiratory rate, systolic blood pressure, heart rate, pulse oximetry, and Glasgow Coma Scale (GCS) score, were categorized according to prior thresholds [11]. We assigned integer points for each category as previously reported (Additional file 1: Table S2) and summed the points to determine the total score (range 0-8) for each EMS encounter. When a necessary variable was missing, we used single-value imputation, assuming normal, as is standard in most critical illness scores $[17,18]$. We used Pearson's chi-square test with $p<0.05$ to assess for a difference in distributions of score values among encounters in which critical illness developed. We assessed model discrimination using the AUROC curve with binomial CIs. Because calibration statistics such as the Hosmer-Lemeshow statistic are often statistically significant in large datasets [19], we evaluated model calibration by graphically assessing a plot of observed versus expected events across the score range. We calculated sensitivity, specificity, and positive and negative predictive values for clinically relevant score thresholds.

\section{Sensitivity analyses}

We performed several sensitivity analyses to assess the robustness of our findings. We explored model performance for alternative definitions of critical illness: (1) the critical illness outcome measured in the primary publication (any one of severe sepsis using the Angus implementation of International Classification of Diseases, Ninth Revision, Clinical Modification [ICD-9-CM], codes [20]; mechanical ventilation $\geq 72 \mathrm{~h}$ from ICD-9CM procedure codes; or in-hospital mortality) [11], (2) an EHR definition using only organ support (either receipt of mechanical ventilation or vasopressor use), and (3) an EHR definition using only in-hospital mortality. We also determined score performance in the following a priori analyses: (1) use of worst vital signs rather than initial vital signs, as these may more accurately reflect patient deterioration; (2) a restricted cohort of patient encounters with transport times greater than the median, as this could inform generalizability to rural EMS systems [21]; and (3) exclusion of patients with Do Not Intubate orders, as these patients may be misclassified by outcome definitions that use mechanical ventilation. Finally, we reweighted the categorized score by rounding beta coefficients of the external validation multivariable logistic regression model to the nearest integers. We then determined if model performance was improved using these reweighted point values [15]. Among sensitivity analyses, we considered a chi-square test result of the AUROC area with $p<0.05$ to indicate a statistically 
significant difference in performance compared with the main risk score. All analyses were performed with STATA 13.0 software (StataCorp, College Station, TX, USA). All tests of significance used a two-sided $p \leq 0.05$.

\section{Results}

Among 59,805 prehospital encounters (Fig. 1), we excluded those less than 18 years of age $(n=871,1.5 \%)$; those with trauma, burn, or fall $(n=6567,11.0 \%)$; those with cardiac arrest $(n=352,0.6 \%)$; and those for whom prehospital risk score data were not available $(n=9201$, $15.4 \%)$. The final cohort consisted of 42,550 encounters in which 1926 patients (4.5\%) developed critical illness during their hospitalization according to the primary definition. Compared with encounters in which patients did not develop critical illness, critically ill patients were older, more frequently male, and more likely to present with prehospital respiratory or neurological symptoms $(p<0.01$ for all) (Table 1). Encounters that developed critical illness were also more likely to receive supplemental oxygen, have peripheral intravenous access established, and undergo endotracheal intubation prior to hospital arrival $(p<0.01)$. Hospital length of stay and inhospital mortality were greater among critically ill patients $(p<0.01)$.

A total of $71.1 \%$ of encounters $(n=30,250)$ had a prehospital risk score of 0 to 1 , while $25.9 \%(n=11,004)$ had a score of 2 or 3 and $3.0 \%(n=1296)$ had a score $>3$. The proportion of patients receiving mechanical ventilation, vasopressors, and intensive care increased with greater prehospital risk scores (Additional file 1: Figure S1). When stratified by critical illness, the prehospital risk scores were higher among the critically ill (Fig. 2$)(p<0.01$ by Pearson's chi-square test). The prehospital risk score demonstrated satisfactory discrimination for critical illness (AUROC 0.73, 95 \% CI 0.72-0.74). Calibration of the risk score was adequate on the basis of observed versus expected plots (Fig. 3). Using a threshold score $\geq 1$ to identify critical illness, we observed a sensitivity of 0.98 (95\% CI $0.97-0.98$ ), specificity of 0.17 (95\% CI $0.17-0.17$ ), positive predictive value of 0.05 (95\% CI 0.05-0.06), and negative predictive value of 0.99 (95\% CI 0.99-1.0). Using a score threshold $\geq 2$ to identify critical illness, sensitivity decreased with little change in positive or negative predictive value (Table 2).

In sensitivity analyses, the AUROC values for models using alternate definitions of critical illness were similar to those in the primary model (Table 3). Prehospital risk score performance was better when worst prehospital vital signs were used $(p<0.01)$, and correlation between first and worst vital signs was high (Pearson correlation coefficient range 0.69-0.91) (Additional file 1: Table S1). Score performance was similar in cohorts restricted to longer than median transport times or those without limitations to life-sustaining therapy. When risk score variables were reweighted using multivariable logistic regression, point scores were different within strata of respiratory rate and GCS score, resulting in a model with range from 0 to 7 points (Additional file 1: Table S2). In the revised model, GCS $<8$ had the greatest weight (integer score of 2 points), compared with the original model in which this stratum and respiratory rate $\geq 36$ shared the greatest weight (integer score of 2 points). The revised model

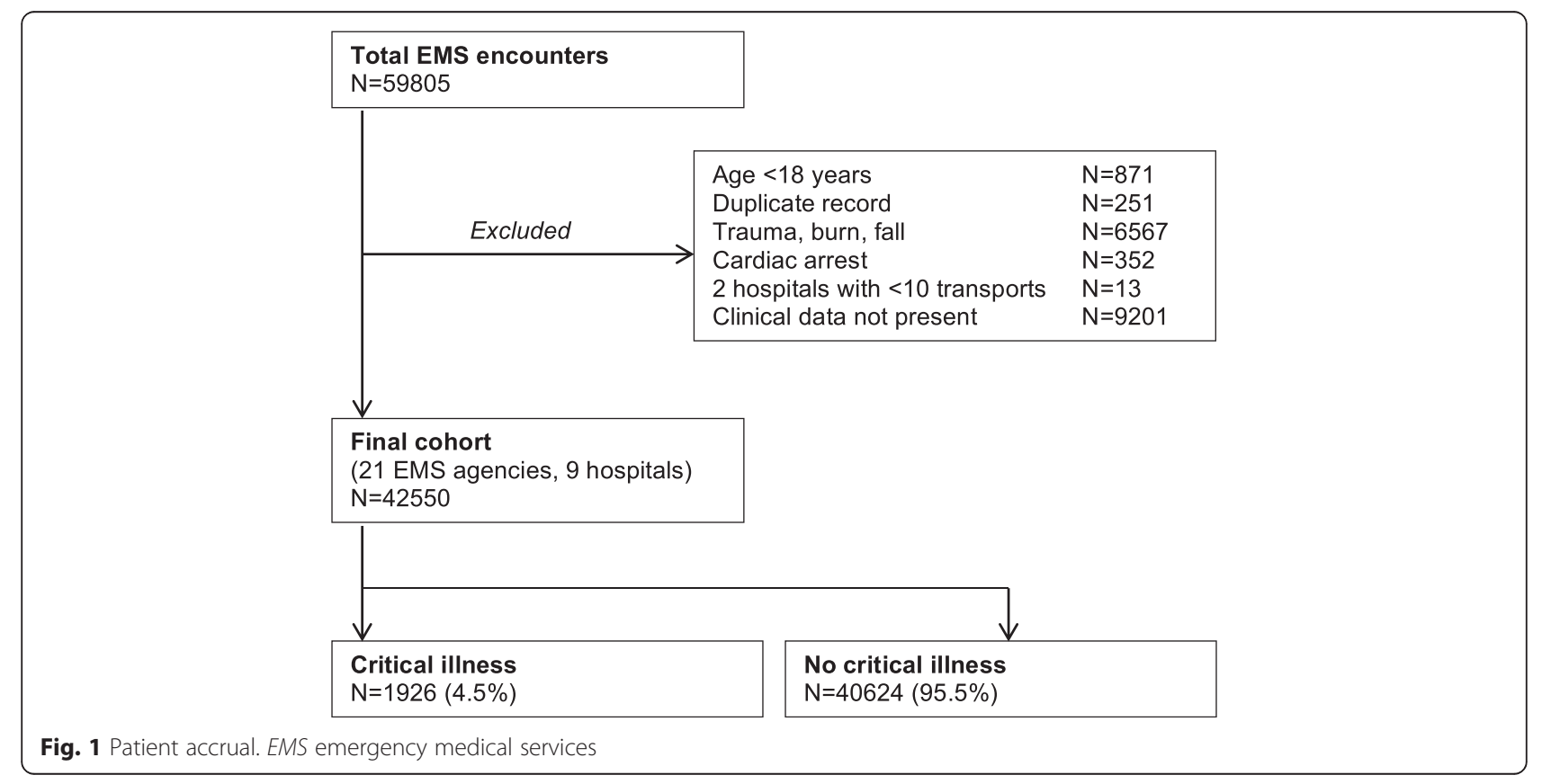


Table 1 Patient characteristics

\begin{tabular}{|c|c|c|c|}
\hline Variable & $\begin{array}{l}\text { Critical } \\
\text { illness }\end{array}$ & $\begin{array}{l}\text { No critical } \\
\text { illness }\end{array}$ & $p$ Value \\
\hline Number of patients (\%) & $1926(4.5)$ & $40,624(95.5)$ & \\
\hline Age, years, mean (SD) & $66(17)$ & $62(21)$ & $<0.01$ \\
\hline Male sex, n (\%) & $929(48)$ & $15,987(39)$ & $<0.01$ \\
\hline EMS staffing level, n (\%) & & & $<0.01$ \\
\hline Critical care & $188(10)$ & $427(1)$ & \\
\hline ALS & $1676(87)$ & $37,646(93)$ & \\
\hline BLS & $61(3)$ & $2540(6)$ & \\
\hline \multicolumn{4}{|l|}{$\begin{array}{l}\text { Initial prehospital vital } \\
\text { signs, mean } \pm \text { SD }\end{array}$} \\
\hline $\begin{array}{l}\text { Systolic blood pressure, } \\
\mathrm{mmHg}\end{array}$ & $131 \pm 36$ & $139 \pm 28$ & $<0.01$ \\
\hline Heart rate, beats/minute & $96 \pm 26$ & $89 \pm 20$ & $<0.01$ \\
\hline $\begin{array}{l}\text { Respiratory rate, } \\
\text { breaths/minute }\end{array}$ & $20 \pm 7$ & $19 \pm 5$ & $<0.01$ \\
\hline Oxygen saturation, \% & $93 \pm 9$ & $96 \pm 10$ & $<0.01$ \\
\hline Glasgow Coma Scale score & $12 \pm 4$ & $14 \pm 2$ & $<0.01$ \\
\hline Diagnostic category, $n(\%)^{\mathrm{a}}$ & & & $<0.01$ \\
\hline Respiratory & $405(21)$ & $4863(12)$ & \\
\hline Neurological & $475(25)$ & $6733(17)$ & \\
\hline Cardiovascular & $180(9)$ & $4199(10)$ & \\
\hline Abdominal & $134(7)$ & $4208(10)$ & \\
\hline Metabolic/endocrine & $22(1)$ & $683(2)$ & \\
\hline Psychiatric/toxicology & $52(3)$ & $1000(2)$ & \\
\hline Fall & $94(5)$ & $4310(11)$ & \\
\hline Obstetric/gynecologic & $1(<1)$ & $374(1)$ & \\
\hline Medical (NOS) & $386(20)$ & $8025(20)$ & \\
\hline Other & $138(7)$ & $2356(6)$ & \\
\hline $\begin{array}{l}\text { Scene to hospital destination, } \\
\text { miles, median [IQR] }\end{array}$ & $6.5[3.5-9.3]$ & $5.8[2.8-8.0]$ & $<0.01$ \\
\hline \multicolumn{4}{|l|}{ Prehospital interventions, n (\%) } \\
\hline Intubation & $128(7)$ & $86(<1)$ & $<0.01$ \\
\hline Supplemental oxygen & $1001(58)$ & $14,626(44)$ & $<0.01$ \\
\hline ECG monitoring & $340(20)$ & $5807(17)$ & $<0.02$ \\
\hline $\begin{array}{l}\text { Peripheral or central } \\
\text { intravenous access }\end{array}$ & $1135(66)$ & $19,160(57)$ & $<0.01$ \\
\hline \multicolumn{4}{|l|}{$\begin{array}{l}\text { Components of critical } \\
\text { illness, n (\%) }\end{array}$} \\
\hline $\begin{array}{l}\text { Ever received mechanical } \\
\text { ventilation }\end{array}$ & $1643(85)$ & $208(<1)$ & $<0.01$ \\
\hline Ever received vasopressor & $912(47)$ & $65(<1)$ & $<0.01$ \\
\hline $\begin{array}{l}\text { ICU location in electronic } \\
\text { health record }\end{array}$ & $1926(100)$ & $3279(8)$ & $<0.01$ \\
\hline $\begin{array}{l}\text { Hospital length of stay, days, } \\
\text { median [IQR] }\end{array}$ & $10[6-17]$ & $2[1-5]$ & $<0.01$ \\
\hline Hospital mortality, n (\%) & $463(24)$ & $447(1)$ & $<0.01$ \\
\hline
\end{tabular}

Abbreviations: EMS emergency medical services, $A L S$ advanced life support, $B L S$ basic life support, NOS not otherwise specified, ECG electrocardiogram, ICU intensive care unit, $I Q R$ interquartile range

${ }^{\text {a} D}$ Diagnostic category was determined by EMS staff impression had discrimination for critical illness similar to that of the primary model $(p=0.77)$.

\section{Discussion}

We externally validated a prehospital risk score that predicts critical illness during hospitalization in a multiagency regional EMS system. The score uses objective variables, including demographics and vital signs, that are commonly recorded during prehospital care to discriminate patients who will develop critical illness. These data help advance efforts to identify non-cardiac arrest, nontrauma patients at greatest risk of critical illness during very early care, an opportunity for rapid risk assessment that may inform direct treatment or triage to centers of excellence.

Researchers in many observational studies have proposed that patients with respiratory failure requiring mechanical ventilation [2], sepsis [7], or critical illness have improved outcomes at higher-volume centers [22]. Critical illness regionalization is often suggested as a strategy to leverage these relationships into higherquality, more efficient care [23]. A primary barrier to efficient regionalization is the absence of validated tools to guide patient triage with critical illness. Our work addresses this knowledge gap by validating a tool for critical illness prehospital triage. Both the overall discrimination and prehospital physiology were similar when we compared the external cohort with the original cohort [11]. Of note, there are strategies for regionalized care that use condition-specific risk assessments such as the 12-lead electrocardiogram and the Los Angeles Prehospital Stroke Screen or the Cincinnati Prehospital Stroke Scale. This prehospital risk score complements these condition-specific tools by functioning as a "score for all" among a heterogeneous group of prehospital encounters, and it could be considered for prospective validation. Additional barriers limit regionalization demonstration projects, including uncertainty over which regions

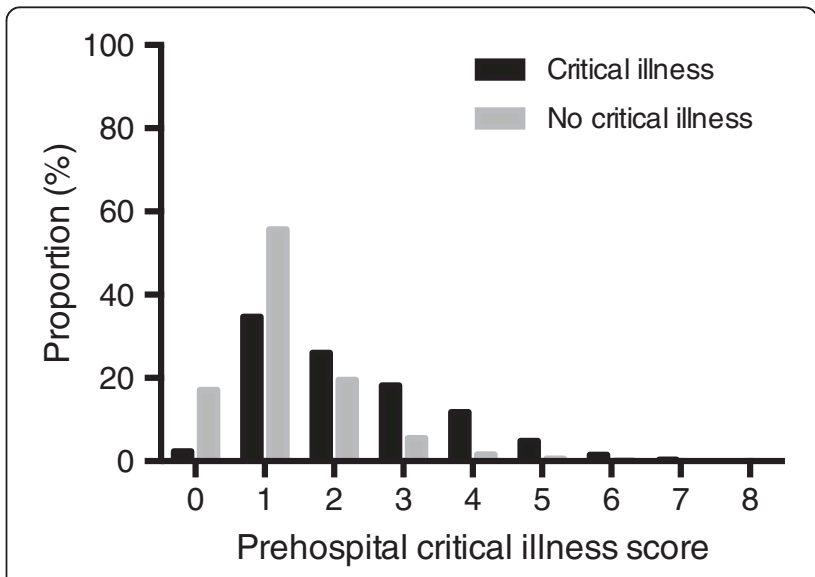

Fig. 2 Distribution of prehospital risk scores of patients with critical illness (black bars) versus those without critical illness (gray bars) 


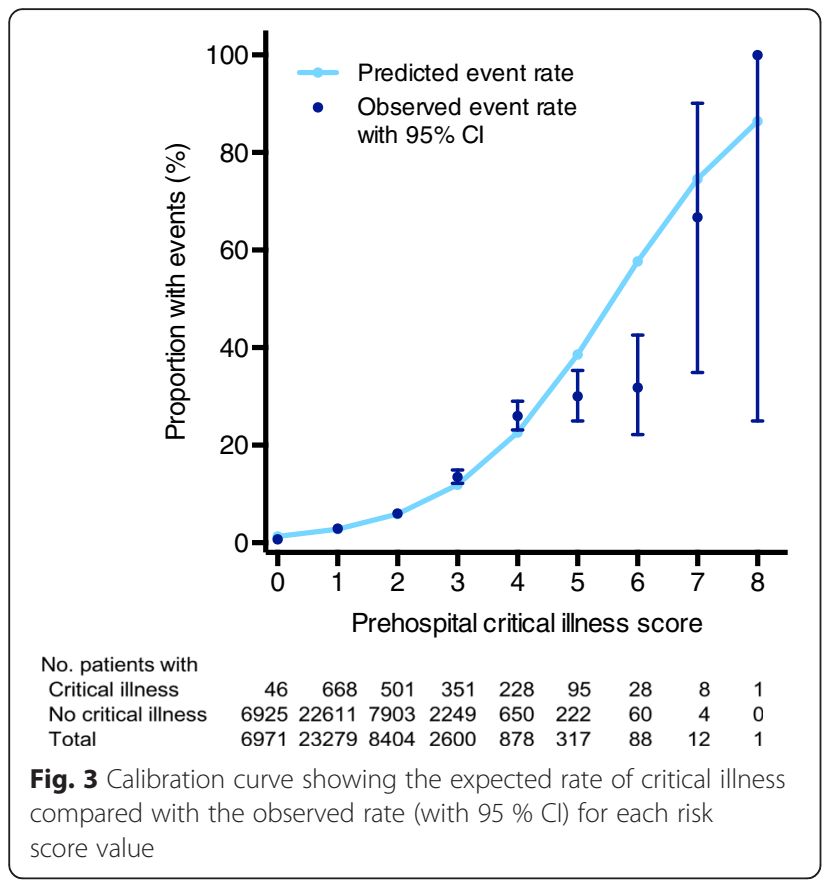

to centralize, lack of stakeholder consensus, and the potential impact of new referral patterns on the financial stability of hospitals and healthcare systems [24]. These challenges will be more feasible to address with a validated triage tool, and careful study of stakeholders' perspectives on patient referrals and the financial effects of regionalization will be necessary prior to and during any demonstration projects.

From a clinical perspective, a prehospital risk score should be both valid and easy to measure. In this study, we assessed the validity of the risk score, but prospective studies of implementation will reveal its timeliness and measurement burden. Because the risk score uses objective, physiologic values routinely recorded during the EMS encounter, it is possible that automated measurement will be feasible, even on mobile devices. The integration of EHRs during EMS care has expanded during the past decade, such that risk models can be determined in a timely fashion and shared with receiving hospitals. Finally, the prehospital risk model provides a foundation upon which potential treatments for the noninjured, non-cardiac arrest patient may be built. Similar to care stratification for prehospital treatment in trauma [25], the prehospital risk score could be used to enrich trials of prehospital interventions for specific risk subgroups.

From a research perspective, the prehospital risk score could be used to standardize and compare otherwise heterogeneous EMS populations. Similarly to risk assessments among hospitalized patients with the Acute Physiology and Chronic Health Evaluation or Logistic Organ Dysfunction System score [17, 26], the prehospital risk score could estimate illness severity during the prehospital phase. These measurements could inform risk adjustment when testing the effectiveness of prehospital interventions on outcome [4]. For quality improvement, the score could identify sentinel, high-risk patients in whom to audit performance, as is used in cardiac arrest, ventilator-associated events, and surgical site infections [27]. The broad applicability of the risk score for these purposes is plausible, as the component variables are data fields already present in the National Emergency Medical Services Information System [28].

We recognize several limitations to our study. There is no gold standard definition for critical illness, so we selected a composite outcome of ICU location in EHRs accompanied by concurrent organ support. Alternative approaches to defining critical illness did not reveal changes in model performance. The risk score's performance could also have been impacted by cohort selection of patients only transported to UPMC hospitals. In general, the cohort characteristics are similar to other large EMS populations in urban, rural, and semirural regions [11]. To favor parsimony and ease of use, we did not seek to maximize model performance by adding variables. We acknowledge that more complex prediction models (e.g., scores with noninteger point values, classification and regression tree analysis) might improve discrimination and calibration, but at the cost of potentially increasing measurement burden. Finally, the organization of other EMS systems may differ from that of this southwestern Pennsylvania cohort. Because the prehospital critical illness score does not involve variables dependent on EMS care or level of training, these differences should have low impact on the external validity of the results.

Table 2 Operating characteristics for prehospital risk score thresholds

\begin{tabular}{|c|c|c|c|}
\hline \multirow[b]{2}{*}{ Operating characteristics } & \multicolumn{3}{|c|}{ Prehospital risk score threshold } \\
\hline & 1 & 2 & 3 \\
\hline Sensitivity, 95 \% Cl & $97.6(96.8-98.3)$ & $62.9(60.7-65.1)$ & $36.9(34.8-39.1)$ \\
\hline Specificity, 95 \% Cl & $17.1(16.7-17.4)$ & $72.7(72.3-73.1)$ & $92.2(91.9-92.4)$ \\
\hline Negative predictive value, $95 \% \mathrm{Cl}$ & $99.3(99.1-99.5)$ & $97.6(97.5-97.8)$ & $96.9(96.7-97.0)$ \\
\hline Positive predictive value, $95 \% \mathrm{Cl}$ & $5.3(5.1-5.5)$ & $9.9(9.3-10.4)$ & $18.3(17.1-19.5)$ \\
\hline
\end{tabular}


Table 3 Discrimination of the prehospital risk score in the primary model, alternative definitions of critical illness, and sensitivity analyses

\begin{tabular}{lcc}
\hline & AUROC & $95 \% \mathrm{Cl}$ \\
\hline Primary model & 0.73 & $0.72-0.74$ \\
Alternative definitions of critical illness & & \\
In-hospital mortality & 0.77 & $0.76-0.79$ \\
Any organ support event & 0.72 & $0.71-0.73$ \\
Administrative claims & 0.71 & $0.70-0.72$ \\
Sensitivity analyses & & \\
Worst vital signs & 0.74 & $0.73-0.75$ \\
Longer than median transport distance & 0.71 & $0.69-0.72$ \\
Excluding patients with Do Not Intubate orders & 0.73 & $0.72-0.75$ \\
Model with reweighting of coefficients & 0.73 & $0.72-0.74$ \\
\hline
\end{tabular}

\section{Conclusions}

In an external validation cohort, a prehospital risk score using objective clinical data had moderate discrimination for critical illness during hospitalization. Although prospective studies and implementation evaluation are required, these data advance support for the use of simple clinical data to triage risk among prehospital, noncardiac arrest, nontrauma patients.

\section{Additional file}

Additional file 1: Figure S1. Proportion of patients across the range of prehospital risk scores with various healthcare use. Table S1. Proportion of patients with abnormal first versus worst vital signs within variable strata, and correlation between first and worst vital signs for each variable. Table S2. Multivariable logistic regression model output of prehospital risk score variables with critical illness showing reweighting in sensitivity analysis. (DOCX 76 kb)

\section{Abbreviations}

ALS, advanced life support; APACHE, Acute Physiology and Chronic Health Evaluation; BLS, basic life support; DNI, Do Not Intubate; ECG, electrocardiogram; EHR, electronic health record; EMS, emergency medical services; GCS, Glasgow Coma Scale; ICD-9-CM, International Classification of Diseases, Ninth Revision, Clinical Modification; ICU, intensive care unit; IQR, interquartile range; NOS, not otherwise specified; UPMC, University of Pittsburgh Medical Center

\section{Acknowledgements}

We acknowledge the contributions of the participating EMS agencies in southwestern Pennsylvania. This work was supported in part by grants from the National Institutes of Health (T32HL007820 and K23GM104022). These funding sources had no role in the design and conduct of the study; the collection, management, analysis, and interpretation of the data; and the preparation, review, or approval of the manuscript.

\section{Authors' contributions}

DRK, CM-G, JMK, CWC, DMY, DCA, and CWS conceived of and designed the study. CM-G and CWS acquired the data. DRK, CM-G, JMK, CWC, DMY, DCA, and CWS analyzed and interpreted the data. DRK and CWS drafted the manuscript. DRK, CM-G, JMK, CWC, DMY, DCA, and CWS critically revised the manuscript for important intellectual content. DRK and CWS performed statistical analysis. CWS provided administrative, technical, or material support. CWS supervised the study. All authors read and approved the final manuscript.

\section{Competing interests}

The authors declare that they have no competing interests.

\section{Author details}

${ }^{1}$ Department of Critical Care Medicine, University of Pittsburgh School of Medicine, 3550 Terrace Street, Scaife Hall \#607, Pittsburgh, PA 15261, USA.

${ }^{2}$ Clinical Research, Investigation, and Systems Modeling of Acute Illness (CRISMA) Center, Pittsburgh, PA, USA. ${ }^{3}$ Department of Emergency Medicine, University of Pittsburgh, Pittsburgh, PA, USA.

Received: 31 March 2016 Accepted: 13 July 2016

Published online: 11 August 2016

\section{References}

1. Federal Interagency Committee on Emergency Medical Services. 2011 National EMS Assessment. Washington, DC: U.S. Department of Transportation, National Highway Traffic Safety Administration; 2011. Available from: http://www.ems.gov/pdf/2011/National_EMS_Assessment_ Final_Draft_12202011.pdf. Accessed 26 Jul 2016.

2. Kahn JM, Goss CH, Heagerty PJ, Kramer AA, O'Brien CR, Rubenfeld GD Hospital volume and the outcomes of mechanical ventilation. N Engl J Med. 2006:355(1):41-50.

3. Kahn JM, Branas CC, Schwab CW, Asch DA. Regionalization of medical critical care: what can we learn from the trauma experience? Crit Care Med. 2008;36(11):3085-8.

4. Seymour CW, Cooke CR, Hebert PL, Rea TD. Intravenous access during outof-hospital emergency care of noninjured patients: a population-based outcome study. Ann Emerg Med. 2012;59(4):296-303.

5. Seymour CW, Cooke CR, Heckbert SR, Spertus JA, Callaway CW, Martin-Gill C, et al. Prehospital intravenous access and fluid resuscitation in severe sepsis: an observational cohort study. Crit Care. 2014;18(5):533.

6. Barnato AE, Kahn JM, Rubenfeld GD, McCauley K, Fontaine D, Frassica JJ, et al. Prioritizing the organization and management of intensive care services in the United States: the PrOMIS Conference. Crit Care Med. 2007; 35(4):1003-11.

7. Walkey AJ, Wiener RS. Hospital case volume and outcomes among patients hospitalized with severe sepsis. Am J Respir Crit Care Med. 2014;189(5):548-55.

8. Levine SD, Colwell CB, Pons PT, Gravitz C, Haukoos JS, McVaney KE. How well do paramedics predict admission to the hospital? A prospective study. J Emerg Med. 2006;31(1):1-5.

9. Suffoletto B, Frisch A, Prabhu A, Kristan J, Guyette FX, Callaway CW. Prediction of serious infection during prehospital emergency care. Prehosp Emerg Care. 2011;15(3):325-30.

10. Seymour CW, Cooke CR, Heckbert SR, Copass MK, Yealy DM, Spertus JA, et al. Prehospital systolic blood pressure thresholds: a community-based outcomes study. Acad Emerg Med. 2013;20(6):597-604.

11. Seymour CW, Kahn JM, Cooke CR, Watkins TR, Heckbert SR, Rea TD. Prediction of critical illness during out-of-hospital emergency care. JAMA. 2010;304(7):747-54.

12. Moseson EM, Zhuo H, Chu J, Stein JC, Matthay MA, Kangelaris KN, et al. Intensive care unit scoring systems outperform emergency department scoring systems for mortality prediction in critically ill patients: a prospective cohort study. J Intensive Care. 2014;2:40.

13. Collins GS, Reitsma JB, Altman DG, Moons KGM. Transparent reporting of a multivariable prediction model for individual prognosis or diagnosis (TRIPOD): the TRIPOD statement. BMJ. 2015:350:97594.

14. Moons KGM, Altman DG, Reitsma JB, loannidis JP, Macaskill P, Steyersberg EW, et al. Transparent Reporting of a multivariable prediction model for Individual Prognosis or Diagnosis (TRIPOD): explanation and elaboration. Ann Intern Med. 2015;162(1):W1-73.

15. Moons KGM, Kengne AP, Grobbee DE, Royston P, Vergouwe Y, Altman DG, et al. Risk prediction models: II. External validation, model updating, and impact assessment. Heart. 2012;98(9):691-8.

16. Seymour CW, Kahn JM, Martin-Gill C, Callaway CW, Angus DC, Yealy DM Creating an infrastructure for comparative effectiveness research in emergency medical services. Acad Emerg Med. 2014;21(5):599-607.

17. Knaus WA, Draper EA, Wagner DP, Zimmerman JE. APACHE II: a severity of disease classification system. Crit Care Med. 1985;13(10):818-29.

18. Vincent IL, de Mendonça A, Cantraine F, Moreno R, Takala J, Suter PM, et al. Use of the SOFA score to assess the incidence of organ dysfunction/failure 
in intensive care units: results of a multicenter, prospective study. Crit Care Med. 1998;26(11):1793-390.

19. Kramer AA, Zimmerman JE. Assessing the calibration of mortality benchmarks in critical care: the Hosmer-Lemeshow test revisited. Crit Care Med. 2007;35(9):2052-6.

20. Angus DC, Linde-Zwirble WT, Lidicker J, Clermont G, Carcillo J, Pinsky MR. Epidemiology of severe sepsis in the United States: analysis of incidence, outcome, and associated costs of care. Crit Care Med. 2001;29(7):1303-10.

21. Grossman DC, Kim A, Macdonald SC, Klein P, Copass MK, Maier RV. Urban-rural differences in prehospital care of major trauma. J Trauma. 1997;42(4):723-9.

22. Glance LG, Li Y, Osler TM, Dick A, Mukamel DB. Impact of patient volume on the mortality rate of adult intensive care unit patients. Crit Care Med. 2006; 34(7):1925-34.

23. Nguyen $\mathrm{YL}$, Kahn JM, Angus DC. Reorganizing adult critical care delivery: the role of regionalization, telemedicine, and community outreach. Am J Respir Crit Care Med. 2010;181(11):1164-9.

24. Seymour CW, Alotaik O, Wallace DJ, Elhabashy AE, Chhatwal J, Rea TD, et al. County-level effects of prehospital regionalization of critically ill patients: a simulation study. Crit Care Med. 2015;43(9):1807-15.

25. Strosberg DS, Nguyen MC, Mostafavifar L, Mell H, Evans DC. Development of a prehospital tranexamic acid administration protocol. Prehosp Emerg Care. 2016;20:462-6.

26. Le Gall JR, Klar J, Lemeshow S, Saulnier F, Alberti C, Artigas A, et al. The Logistic Organ Dysfunction System: a new way to assess organ dysfunction in the intensive care unit. JAMA. 1996;276(10):802-10.

27. Travers AH, Rea TD, Bobrow BJ, Edelson DP, Berg RA, Sayre MR, et al. Part 4: CPR overview: 2010 American Heart Association guidelines for cardiopulmonary resuscitation and emergency cardiovascular care. Circulation. 2010;122(18 Suppl 3):S676-84.

28. National EMS Information Systems. Available from: http://www.nemsis.org/. Accessed 29 Mar 2016

\section{Submit your next manuscript to BioMed Central and we will help you at every step:}

- We accept pre-submission inquiries

- Our selector tool helps you to find the most relevant journal

- We provide round the clock customer support

- Convenient online submission

- Thorough peer review

- Inclusion in PubMed and all major indexing services

- Maximum visibility for your research

Submit your manuscript at www.biomedcentral.com/submit

) Biomed Central 